\title{
造影剤を配合したオレイン酸エタノールアミン注射液の調製
}

板倉忠則, 馬淵和英, 片桐義博*1, 秋山美岐,

野津芳正 ${ }^{* 2}$, 山本 俊, 河合利夫*3

島根医科大学医学部附属病院薬剂部*1

平田市立病院薬郕科*2, 同内科*3

\section{Preparation of Ethanolamine Oleate Injection Mixed with Contrast Medium}

\author{
TADANORI ITAKURA, KAZUHIDE MABUCHI, YOSHIHIRO KATAGIRI*1, \\ Miki AKiyama, Yoshimasa NozU*2, Shun Yamamoto, \\ and TOSHIO KAWAI*3 \\ Department of Pharmacy, Shimane Medical University Hospital*1 \\ Department of Pharmacy*2, and Internal Medicine*3, Hirata Municipal Hospital
}

(Received July 29, 1986)

\begin{abstract}
Ethanolamine oleate injection has been used as a sclerosing agent in the treatment of esophageal varices. We prepared 4 kinds of sclerosing agents for visualizing varices by mixing ethanolamine oleate with contrast media, iopamidol and meglumine amidotrizoate injections. The viscosities and osmotic pressures of these agents were measured. The time required to discharge a given volume of each agent through a syringe, a tube and a puncture needle under the pressure of $2 \mathrm{~kg} / 2.6 \mathrm{~cm}^{2}$ was measured. The ability of visualization was observed by $X$-ray fluoroscopy. Ethanolamine oleate injection containing 30\% iopamidol (EO-IP 30) was less viscous. Furthermore, the value of osmotic pressure of EO-IP30 was almost the same as that of normal saline. The viscosity of the agent was related to the time required discharge a given volume of the agent. The time for a discharge of EO-IP 30 was shortest. Good fluoroscopic visualization was obtained in all preparations. These results suggest that EO-IP 30 is a useful agent for injection sclerotherapy of esophageal varices.
\end{abstract}

Keywords - ethanolamine oleate (EO); iopamidol; meglumine amidotrizoate; contrast medium; sclerosing agent; esophageal varix; injection sclerotherapy; viscosity; osmotic pressure

\section{楮}

食道静脈溜に対する治療として，内視鏡的硬化柽塞療 法が普及してきている．現在使用されている硬化栓塞剤 (烃塞郕)は, $5 \%$ ethanolamine oleate (EO) ${ }^{1,2}, 1 \%$ polidocanol $^{3)}, 5 \%$ sodium morrhuate ${ }^{4)}, 2 \%$ sodium

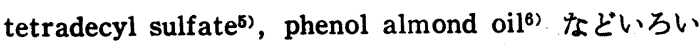
ろなるのがある.この中で，5\% EOを用いての食道静

*1 出雲市塭冶町89-1；89-1，Enya-cho， Izumo-shi， 693 Japan

*2,3 平田市灌分町 613; 613, Nadabun-cho, Hiratashi, 691 Japan
脈瘤に対する内視鏡的栓塞療法は, わが国では高瀬ら ${ }^{1,2)}$ によって初めて施行され良好な臨床評価がなされてい る. その後, 多数の使用例が報告され, 注入方法, 注入 量などについても詳しく検討が進められてきた。しか し，EO は注入時に血管周囲組織に漏出した場合，潰瘍 形成, 組織壊死等の重篤な副作用を生じる.したがっ て, 注入の際は細心の注意が必要である.また適正な注 入量の確認ができず，その改善が望まれてきた。

そこで, 注入時の血管外漏出の監視や注入量の適正化 等の目的で, EO に血管造影剤を配合し, X線透視下で 注入状況を確認できる製剤の調製が試みられてきた。武 田らクはEOルイオン性である血管造影剤のアミドトリ 
ソ酸メグルミン注射液 (meglumine amidotrizoate, MA) を 40\%配合した製剂（EO-MA 40）を調製しま たそれは臨床上る使用されている8).ささらに, 非イオン 性の血管造影剂であるイオパミドール注射液 (iopamidol, IP) を46\%配合した製剤（EO-IP 46）試作され ている9.

われわれはこの EO-MA 40 を調製し臨床使用を試 みた.しかし、この製剤は粘度が高いため, 製造工程で のろ過が困難であり, また食道静脈瘤への注入る困難で あった. そこで,これらの点を改善しさらに臨床的にも 十分使用し得る製剤の調製を試みた。これまで栓塞剤に 配合されて臨床的に用いられている MA の濃度を $30 \%$ にした製剂 (EO-MA 30)，および IP を 30\%配合した 製剤 (EO-IP 30) を調製し, その性状について従来のも のと比較検討したので報告する.

方法

\section{1. 試料の倜慗}

調製した製蝺の処方を Table 1 に示した．EO】は英 国薬局方 ${ }^{10}$ に従って調製した。また造影剤を配合した注 射液は以下の方法によった. オレイン酸 $4.23 \mathrm{~g}$ を秤量 し, 注射用蒸留水を加えて振とらする.これにあらかじ めエタノールアミン0.91 g を溶解した水溶液を加え振と らする. 次にベンジルフルコール $2 \mathrm{ml}$ を加え振とらす る. 静置後, 注射用蒸留水を加え $50 \mathrm{ml}$ とする. 造影剂 として IP を,それぞれ $30 \mathrm{ml}$ および $46 \mathrm{ml}$ 加え, 注 射用蒸留水で全量 $100 \mathrm{ml}$ とする. 造影剤として MA を
加える場合は,上述のベンジルアルコールの量は $5 \mathrm{ml}$ と し, MA をそれぞれ $30 \mathrm{ml}$ および $40 \mathrm{ml}$ 加え, 全量 $100 \mathrm{ml}$ とした。調製した注射液はフィルター（マイレ ックス-HA， $0.45 \mu \mathrm{m}$ ) でろ過し, 褐色アンプルに分注 後封入し，オートクレーブで隇菌 $\left(115^{\circ} \mathrm{C}, 30\right.$ 分) した.

\section{2. 比而およひ粘度の测定}

日本薬局方Xの比重測定法に従って, ピクノメーター を用い $30^{\circ} \mathrm{C}$ に打ける比重を測定した。

粘度は, 日本薬局方Xの粘度測定法に従って, ウべロ 一デ粘度計を用いて $30^{\circ} \mathrm{C}$ で測定した. さらにその温度 における密度を測定し, 絶対粘度を求めた. $30^{\circ} \mathrm{C}$ に打 ける蒸留水の絶対粘度を1.00とした場合の試料の相対粘 度を求めた。

\section{3. 湓透圧の测定}

試料の浸透圧をアドバンス浸透圧計 model $3 \mathrm{~W}$ を用 いて測定し，生理食塩水に対する浸透圧比を求めた。

\section{4. 注入の嚾易度（排出時间）}

臨床に使用する場合の注入操作の難易を判定するため に, 実際に臨床で使用する注射筒（ガラス製， $20 \mathrm{ml}$, $18.3 \mathrm{~mm}$ I.D.)，チューブ (テフロン製, 0.65 I.D. $\times$ $1600 \mathrm{~mm}$ ) および穿刺針（テフロン製，22G）を用いて Fig. 1 の装直を作成した. 注射筒に一定量 $(15 \mathrm{ml})$ の 試料を取り, 三方活柽およびチューブを連結後, 注射筒 のピストンに $2 \mathrm{~kg}$ を加重し，穿刺針先端より試料がす べて押し出されるのに要する時間（排出時間）を測定し た。

Table 1. Formula of Ethanolamine Oleate Preparations

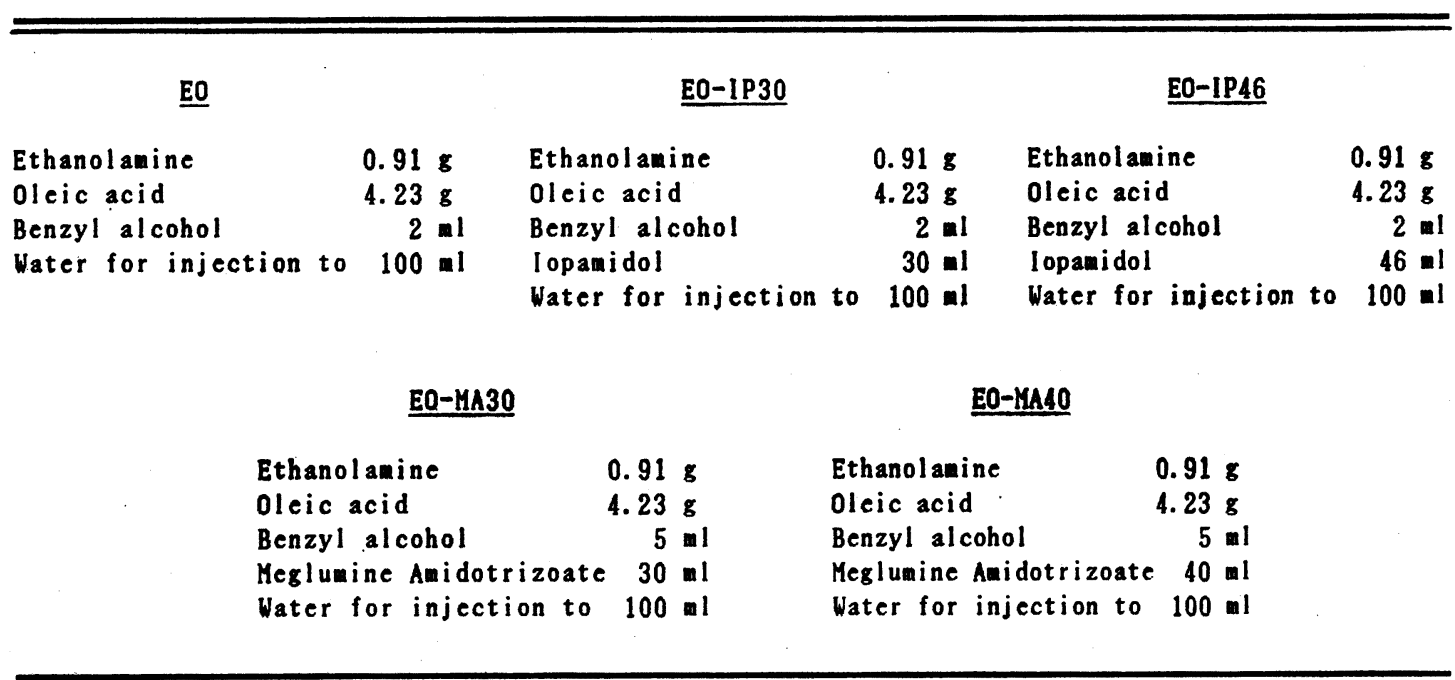




\section{5. 造影能の㛟时}

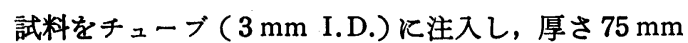
のアクリル板 2 枚汇摤み,ファントーム厚を $150 \mathrm{~mm}$ と 乙, 管電圧 $60 \mathrm{KV}$ ，管電流 $250 \mathrm{~mA}$ ，照射時間 $0.16 \mathrm{sec}$. の条件でX線撮影した。

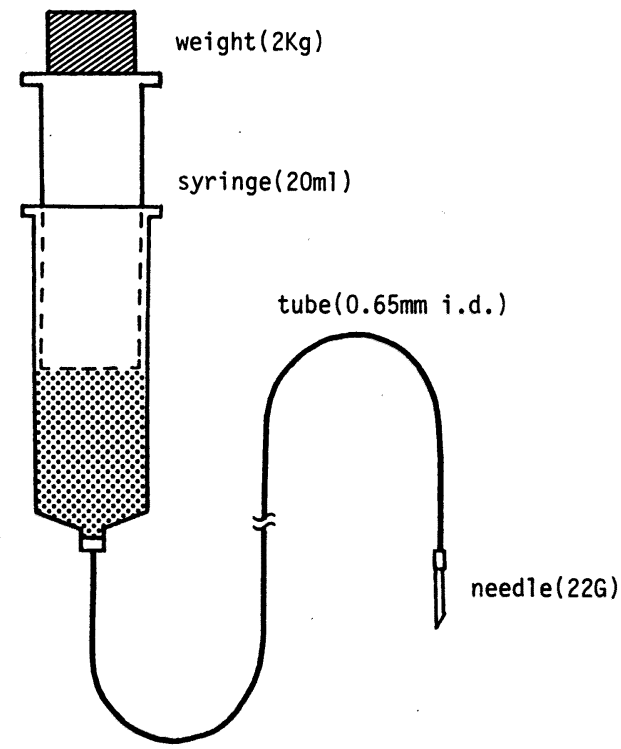

Fig. 1. Apparatus for Measurement of Time for Discharge
結果

\section{1. 比重および粘度}

EO および造影剂を配合した EO の比重および粘度を 測定し，その結果を Table 2 飞示した. EO の比重は 蒸留水とほぼ同程度であったが, 造影剤を配合すると比 重は若干大きくなり， EO-IP 30 および EO-MA 30 が 約 1.10，EO-IP 46 および EO-MA 40 が約1.15の值を 示した。また， $30^{\circ} \mathrm{C}$ に打ける蒸留水の絶対粘度を 1.00 とした時の EO の相対粘度は 2.16 であった. 造影剤を 配合すると相対粘度は大きくなり，IP を $30 \%$ 配合する と3.66，46\%配合で4.83，MA を30\%配合すると 6.83 , 40\%配合で8.25であった. 粘度を下げる目的で添加した ベンジルアルュールの量は EO-IP の方が少ないにもか かわらず，MA を配合した場合に比べて IP 配合の場合 が相対粘度は小さかった。

\section{2. 漫透圧}

生理食塩水に対する浸透圧比を Table 3 亿示した. EO 単独の場合の浸透圧比は0.39でかなり低いが，EOIP 30 は1.27と最も生理食塩水飞近い值を示した。また EO-IP 46 の浸透圧比は1.75であった．MA を配合した 場合は，IP を配合した場合に比較してかなり高い值を 示し，EO-MA 30 および EO-MA 40 の浸透圧比はそれ ぞれ2.71と3.42であった。

Table 2. Specific Gravity and Relative Viscosity at $30^{\circ} \mathrm{C}$

\begin{tabular}{lcccccc}
\hline & $H_{20}$ & EO & EO-IP30 & EO-IP46 & EO-MA30 & EO-MA40 \\
\hline $\begin{array}{l}\text { Specific } \\
\text { Gravity }\end{array}$ & 1.000 & \pm .003 & 1.103 & 1.159 & 1.1111 & 1.144 \\
$\begin{array}{l}\text { Relative } \\
\text { Viscosity }\end{array}$ & 1.00 & 2.0016 & \pm 0.0004 & \pm 0.0010 & \pm 0.0019 & \pm 0.0011 \\
\hline
\end{tabular}

Each value represents the meantSD of 5 determinations

Table 3. Osmotic Pressure (mOsm/kg) and Their Ratio to Normal Saline

\begin{tabular}{|c|c|c|c|c|c|c|}
\hline & $\begin{array}{l}\text { Normal } \\
\text { Saline }\end{array}$ & EO & E O-I P 30 & E $0-I$ P 46 & E $0-M A 30$ & EO-MA 40 \\
\hline $\begin{array}{l}\text { Osmotic } \\
\text { Pressure }\end{array}$ & 281 & $\begin{array}{r}111 \\
\pm 0.3\end{array}$ & $\begin{array}{r}357 \\
\pm 1.7\end{array}$ & $\begin{array}{r}4.90 \\
\pm 2.9\end{array}$ & $\begin{array}{r}762 \\
\pm 1.7\end{array}$ & $\begin{array}{r}962 \\
\pm 13.1\end{array}$ \\
\hline Ratio & 1.00 & $\begin{array}{l}0.39 \\
\pm 0.004\end{array}$ & $\begin{array}{l}1.27 \\
\pm 0.004\end{array}$ & $\begin{array}{l}1.75 \\
\pm 0.012\end{array}$ & $\begin{array}{r}2.71 \\
\pm 0.007\end{array}$ & $\begin{array}{r}3.42 \\
\pm 0.048\end{array}$ \\
\hline
\end{tabular}

Each value represents the mean $\pm S D$ of 6 determinations 


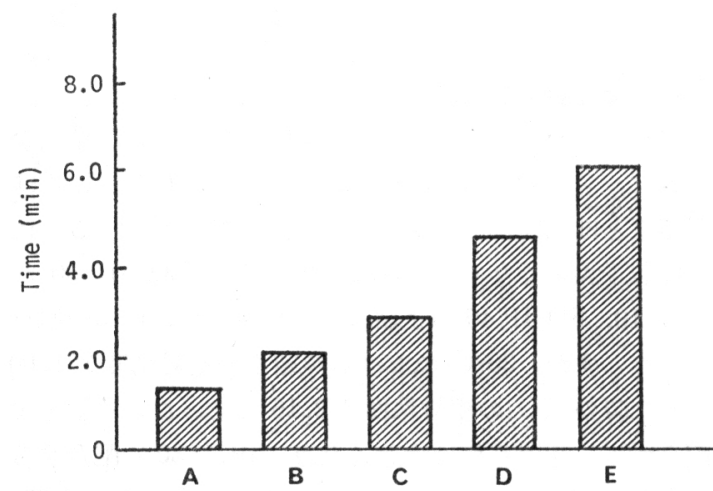

Fig. 2. Times for Discharge of Ethanolamine Oleate Preparations
A : EO, B : EO-IP30, C : EO-IP46,
D : EO-MA30, E : EO-MA40

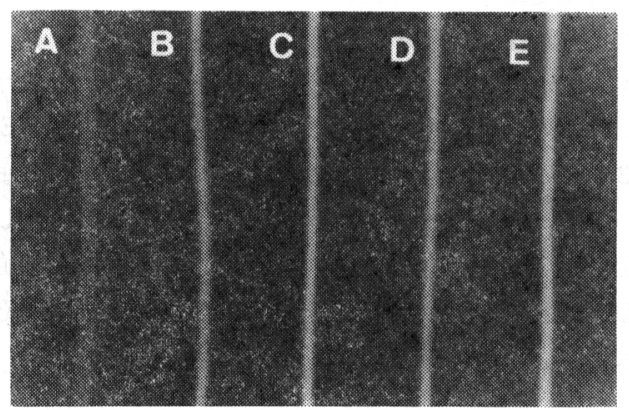

Fig. 4. Radiogram of Ethanolamine Oleate Preparations
A : EO, B : EO-IP30, C : EO-IP46,
D : EO-MA30, E : EO-MA40

\section{3. 排出時間}

臨床に実際用いる器具を利用して, 注入操作の難易を 排出時間で比較した結果を Fig. 2 に示した。注射筒へ の加重により一定量の試料がチューブを通して穿刺針先 端より押し出されるのに要する時間は, EO 単独の場合 は1.3分であった，造影剤として IPを30\%配合した場 合は2.1分，46\%で2.9分，また MA を30\%配合した場 合は 4.7 分， $40 \%$ で 6.2 分であった。

蒸留水に対する相対粘度と, 蒸留水に対する相対時間 との関係を Fig. 3 に示した. 相対粘度が大さくなるに つれて排出時問の比は協合的に大きくなった。

\section{4. 造影能}

試料を臨床に近い条件でX線撮影した結果を Fig. 4 に示した。 $\mathrm{EO}$ 単独の場合は造影されないが，IP およ び MA を配合した試料は十分な造影能を有していた. 特に EO-IP 30 以造影剂が $30 \%$ と低濃度にもかかわら

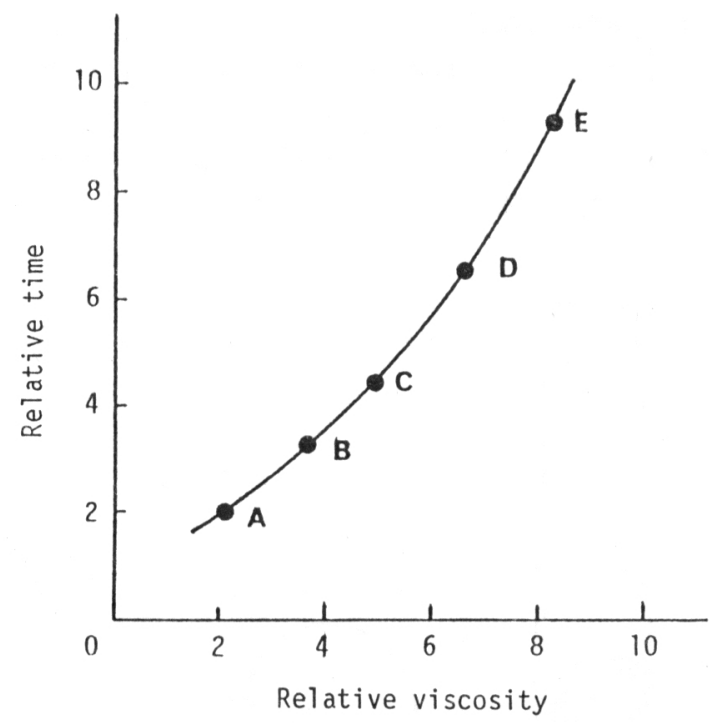

Fig. 3. Relationship between Relative Viscosity and Time for Discharge

A : EO, B : EO-IP30, C : EO-IP46,

D : EO-MA30, E : EO-MA40

ず，IP を46\%および MA を30\%，40\%配合の製剤と同 程度の造影能を有していた。

\section{考察}

食道静脈瘤の栓塞療法に用いられる EO に, 血管外漏 出の監視や適正な注入量把握の目的で造影剂を配合する ことがある、そのために造影剂の MA は従来から用い られてきたが, その粘度が高いため, 製剤の粘度を低下 する目的でベンジルアルコールを $5 \%$ 添加することが試 みられている。しかし, ペンジルアルコールは呼吸器系 障害や溶血作用を有するため, その添加量は少ないこと が望ましいと考光られる. 今回, われわれが用いた IP は MA より粘度が低いため, ベンジルアルュールの添 加量を $2 \%$ に抑壳ることができた. 従来用いられている EO-MA 40 は, その粘度が EO の久の場合の3.8倍之高 いそここで粘度を低下させるために MA の濃度を $30 \%$ に抑光ても EO の3.2倍の粘度を示し, 粘度は期待した 活ど低下しない、MA の代わりに IPを用いた場合は, 粘度は低く, EO-IP46 で EO の 2.2 倍, 特に, 今回検 討した EO-IP 30 では EO の1.7倍と EO-MA 40 に比 ベて粘度は低く, EO のみの場合に近い值であった。こ のことは EO-MA 40 に比べて製剂工程上でのろ過が簡 単であり，また臨床使用時の注入の容易さを示唆してい るものと考える.

造影剂はイオン負荷, 浸透圧および化学毒性の三つの 
特性を持ち，副作用と関連している．今回用いた非イオ ン性造影剂 IP はイオン負荷がなく低浸透圧であるた め, これらに起因する副作用がかなり軽減されると考兄 られる。.今まで用いられてきた造影郕配合の製剂 EOMA 40 の生理食塩水に対する浸透圧比は，3.42であり， かなり高浸透圧であった．今回調製した製剤のなかで EO-IP 30 は漫透圧比が1.27であり, 最も生理食塩水に 近い值を示し，他の製剤に比べて副作用が少ないことが 考えられる。

これまでは，臨床使用時の注入の難易を製剤の粘度だ けで判断していたそそこでわれわれは臨床により近い条 件での判定を試みた． 注射筒への $2 \mathrm{~kg}$ の加重により一 定量の製荗が押し出されるのに要する時間は，EO 単独 の場合に比べて，EO-MA 30 および EO-MA 40 ではそ れぞれ3.7倍および4.8倍を要したＩP を配合した場合 はその時間は短く，特に EO-IP 30 では EO の1.7倍を 要したにすぎず, 従来用いられてきた EO-MA 40 と比 べて臨床使用時もかなり注入しやすいものと考えられ る.

粘度と排出時間との間には密接な関連性が認められ。 粘度が高くなれば排出に要する時間が長くなる。すなわ ち，製剤の粘度を低下させればより注入が容易となり， したがって配合する造影剤やその濃度を考慮することが 必要である.

造影剂を配合した柽塞剤は，X線透視下でその注入状 態を確認するために十分な造影能を有することが必要で ある．MA を $40 \%$ 配合した製剂は，十分な造影能を有 することが臨床上すでに確認されている8．調製した製 剤のなかで EO-IP 30 は, 造影剤配合の他のるのと同程 度の造影能を有して括り，臨床的にも十分使用可能であ
ると考えられる．今回われわれが調製 した EO-IP 30 は, 従来から臨床上用いられている EO-MA 40 中, 試 作されている EO-IP 46 亿比較して, 粘度, 注入のしゃ すさ，造影能等からみて最も優れた製剤であり，臨床的 にも十分使用できるるのと考えている.

竍辞 本研究にあたり，で協力いただいた島根医大病 院中央放射線部，並びに日本シェーリング株式会社に深 謝いたします。

文献

1）高瀬靖廣, 岩島洋治, 南風原英夫, 名越和夫, 更 科広実, 竹島徹，尾䐀梓，深尾立，岡村隆夫，宮 本二郎, 中原朗, 川北勲, 小山捷平, 福富久之, 绮田隆夫 : Progress of Digestive Endoscopy, 12, 105 (1978)

2) 高瀬靖廣, 中原 朗 : Progress of Digestive Endoscopy, 13, 34 (1978).

3）鈴木博昭, 長尾房大 : 臨 床 成人病, 12,2307 (1982).

4) 二川俊二, 岩崎甫, 深沢正樹, 杉浦光雄 : 消化器 外科, 3, 363 (1980).

5）大橋 满: Gastroenterological Endoscopy, 26, 2517 (1984).

6）熊谷義也，幕内博康，勝呂芳正，三吉博，飯田修 平, 都築俊治 : 消化器外科, 4，1445 (1981)。

7）武田光志, 須賀肇, 家田重義, 吉野清高, 町島啓, 高瀬靖廣, 岩崎洋治：病院薬学，10，35 (1984)。

8) Takase Y., Orii K., Ozaki A., Iwasaki Y. : Asian Med. J., 27, 345 (1984).

9）武田光志, 新井克明, 家田重義, 吉野清高, 町島 啓, 高瀬靖廣, 岩崎洋治 : 病院薬学, 10,446 (1984).

10) "British Pharmaceutical Codex", 1973, p. 713. 